Avance de Investigación

\title{
EXPANSION E INTERNACIONALIZACIÓN DE LAS PYMES AGROINDUSTRIALES COLOMBIANAS ${ }^{1}$
}

\author{
David Guillermo Puyana Silva, Director \\ Grupo de Investigación y Desarrollo de MIPYMEs \\ Escuela de Negocios y Ciencias Empresariales \\ Universidad Sergio Arboleda
}

\section{Resumen}

En este artículo se presentan brevemente aspectos de la problemática que ha vivido el sector empresarial de las micro, pequeñas y medianas empresas (MiPyMEs) del subsector de la agroindustria colombiana en desarrollo de un trabajo investigativo desarrollado por el Grupo de Investigación y Desarrollo de MiPyMEs dentro de su línea de investigación.

Al realizar esta investigación sobre este sector en la ciudad de Bogotá, se ha llegado a obtener una serie de conclusiones que han permitido hacer unas recomendaciones dirigidas a estructurar una propuesta de un modelo de internacionalización para las pymes agroindustriales colombianas, a partir de conocer el estado actual del sector a nivel nacional e internacional, las cuales se presentan como los resultados de la investigación alcanzados hasta ahora. 


\section{Abstract}

This paper presents several topics about the problems in different contexts faced by the colombian small and medium sized enterprises (SMEs) of the agricultural sector as a part of the research study the author is working in.

During the research in the SMEs in the city of Bogotá and after revised in an exhaustive way an extensive literature, it has reaching different solutions and tools to solve the internacionalization problem of them, starting with the status today at the national and international level. This article focuses in four tools to overcome the weakness of export culture of the sector.

\section{Palabras Claves}

Pymes - Agroindustriales - Internacionalización - Globalización - Acuerdos comerciales - Tratado de libre comercio - Franquicias - Inversión extranjera directa - Asociatividad empresarial - E-commerce - B2C

\footnotetext{
${ }^{1}$ Informe de Avance No. 6 del proyecto de investigación que, con este mismo nombre, adelanta el Grupo de Investigación y Desarrollo de MiPyMEs del Departamento de Investigaciones de la Escuela de Negocios y Ciencias Empresariales de la Universidad Sergio Arboleda.
} 


\section{Introducción}

En los diferentes eventos académicos que se han venido sucediendo sobre la problemática de las micro, pequeñas y medianas empresas y la ocupación que sobre el mismo tema han venido haciendo los diferentes medios de comunicación, se destaca la especial importancia que tiene este sector como generador de empleo, promotor de avances en el entorno local y su potencialidad para convertirse en un importante complemento del trabajo de la gran empresa, como lo demuestran las experiencias que han tenido lugar en Italia (Emilia Romana y Modena), Alemania (Baden-Wüttembarg) y Estados Unidos (Sillicon Valley), entre otras, por lo que el mundo lo ha considerado como un sector empresarial muy dinámico y poseedor del mayor potencial de desarrollo productivo (en relación con su tamaño).

Sin embargo, respecto al país y no obstante que las MiPyMEs generan una parte muy significativa de la riqueza productiva $\mathrm{y}$ del empleo nacional $\mathrm{y}$ constituyen un elemento clave en la reducción de los desequilibrios regionales, Colombia tuvo que pasar por varias bonanzas externas de corta duración, y caer en su crisis más profunda (1999) en casi un siglo, para descubrir que siempre ha sido un país de MiPyMEs, siendo su contribución social incalculable por ser los 
vehículos más efectivos para las políticas territoriales y en la coyuntura actual las únicas unidades productivas generadoras de nuevos empleos, además de ser el sector más importante de desarrollo de la economía nacional, gracias a la gran capacidad que tiene de generar rápidamente nuevas fuentes de trabajo para los sectores socialmente débiles; es también muy versátil para adaptarse a las cambiantes exigencias de la demanda, no requieren grandes inversiones y permite una mejor distribución del ingreso; además de que tiene gran potencial de crecimiento y activa la economía local

De otra parte, la globalización de los mercados es un fenómeno corriente en la actual economía y desde hace varios años venimos asistiendo a una desaparición paulatina de las barreras comerciales, a la vez que se van creando nuevos bloques económicos que en otros tiempos hubieran sido impensables. Esto confirma que los nacionalismos económicos no son eternos y que el cosmopolitismo ya no es monopolio de algunas empresas particulares, sino la característica de cualquier mercado en cualquier parte del mundo y lo que es más importante es la obligación de una empresa, cualquiera sea su tamaño: el internacionalizarse.

Movidas por la recesión y debilidad de la demanda interna y los acuerdos comerciales de integración en ciernes que, si bien ofrecen oportunidades de crecimiento también pueden verse golpeadas muy duramente, algunas PyMEs (no todas como fuera de desear) han empezado a adoptar una cultura exportadora 
y se han venido preparando para enfrentar los retos que les depara el proceso de globalización que vive la economía mundial, empezando a hacer exportaciones, aunque solo en promedio dedican un $14 \%$ de su producción al mercado externo y solo contribuyen con menos del $20 \%$ al total de las exportaciones del país, cuando las PyMEs de Taiwan contribuyen con el 57\% y las de Italia con el 52\% del total de las divisas anuales percibidas por esos países.

Sí las PyMEs colombianas iniciaran un desarrollo parecido -mirando al mundo como su mercado- grande sería su aporte a la balanza de pagos y a la generación de empleo, para lo cual es necesario poner en marcha (gobierno, sector privado y academia) un acelerado y vigoroso proceso de internacionalización de nuestras micro, pequeñas y medianas empresas, para aprovechar las oportunidades competitivas, las opciones y ventajas tecnológicas y los incentivos gubernamentales que el país ofrece.

\section{LAS PYMES AGROINDUSTRIALES COLOMBIANAS}

El sector agropecuario en la economía mundial se ha caracterizado por ser el sector con mayores distorsiones en el mercado mundial que desvirtúan la economía de libre mercado, no obstante lo cual hemos considerado posible superar el atraso en su internacionalización que muestra este sector en el país, dadas claras ventajas comparativas como son: riqueza y diversidad de sus recursos naturales, estratégica situación geográfica con cosechas todo el año, relativo mínimo tiempo de transporte a mercados internacionales estacionales, 
Revista electrónica de difusión científica - Universidad Sergio Arboleda Bogotá - Colombia

http://www.usergioarboleda.edu.co/civilizar Reservados todos los derechos de autor Junio 2005

colonias latinas que añoran los productos tropicales y ahora, la liberación del comercio que podría obtenerse, gracias al TLC con Estados Unidos.

CARACTERÍSTICAS DEL SECTOR

1. El sector agropecuario colombiano presenta una balanza comercial superavitaria.

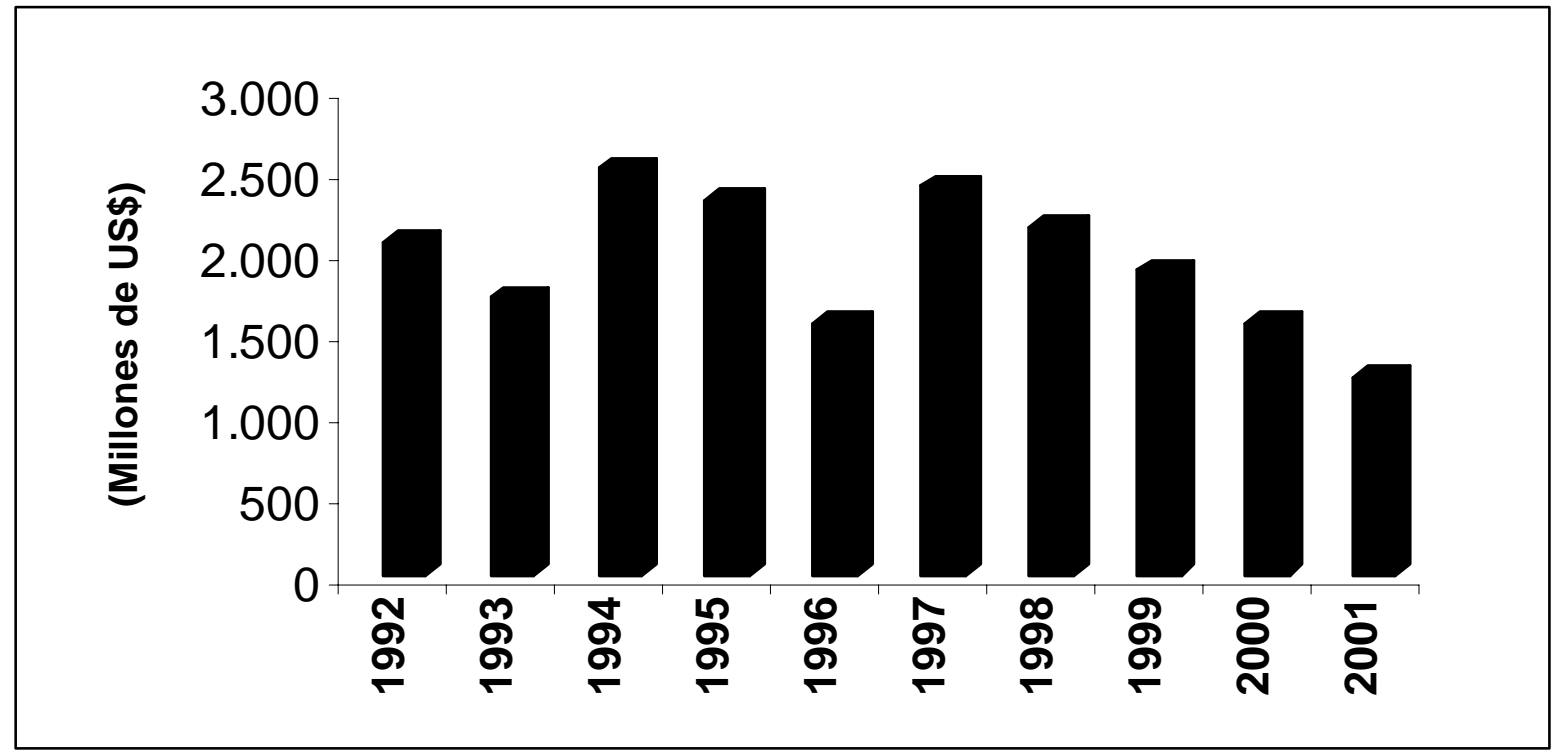

Fuente: Ministerio de Agricultura y Desarrollo Rural (2001)

* El sector agropecuario colombiano es heterogéneo en cuanto al comercio exterior: 


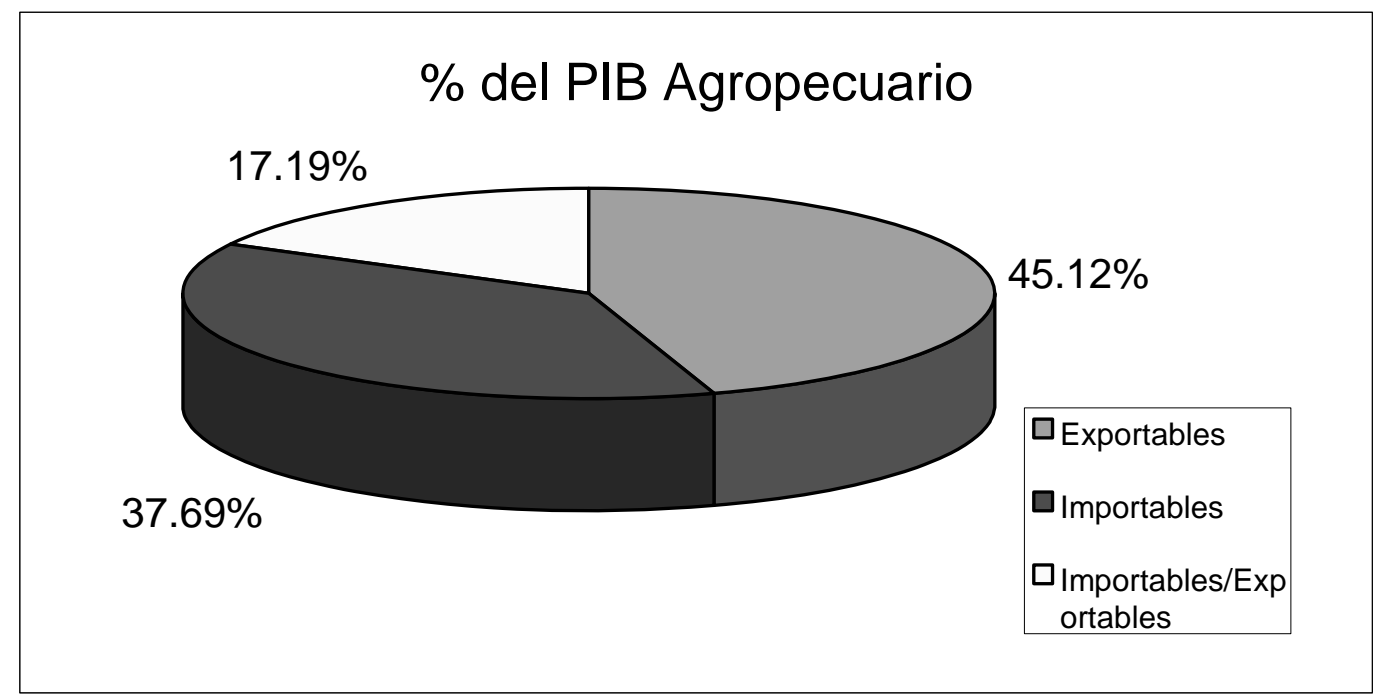

Exportables: Productos exportadores netos, Importables: Importadores netos, Imp/Exp:

Prácticamente equilibrio entre oferta y demanda doméstica

Fuente: Cálculos del Ministerio de Comercio, Industria y Turismo con base en MADR (2001)

\subsection{Principales productos de exportación}

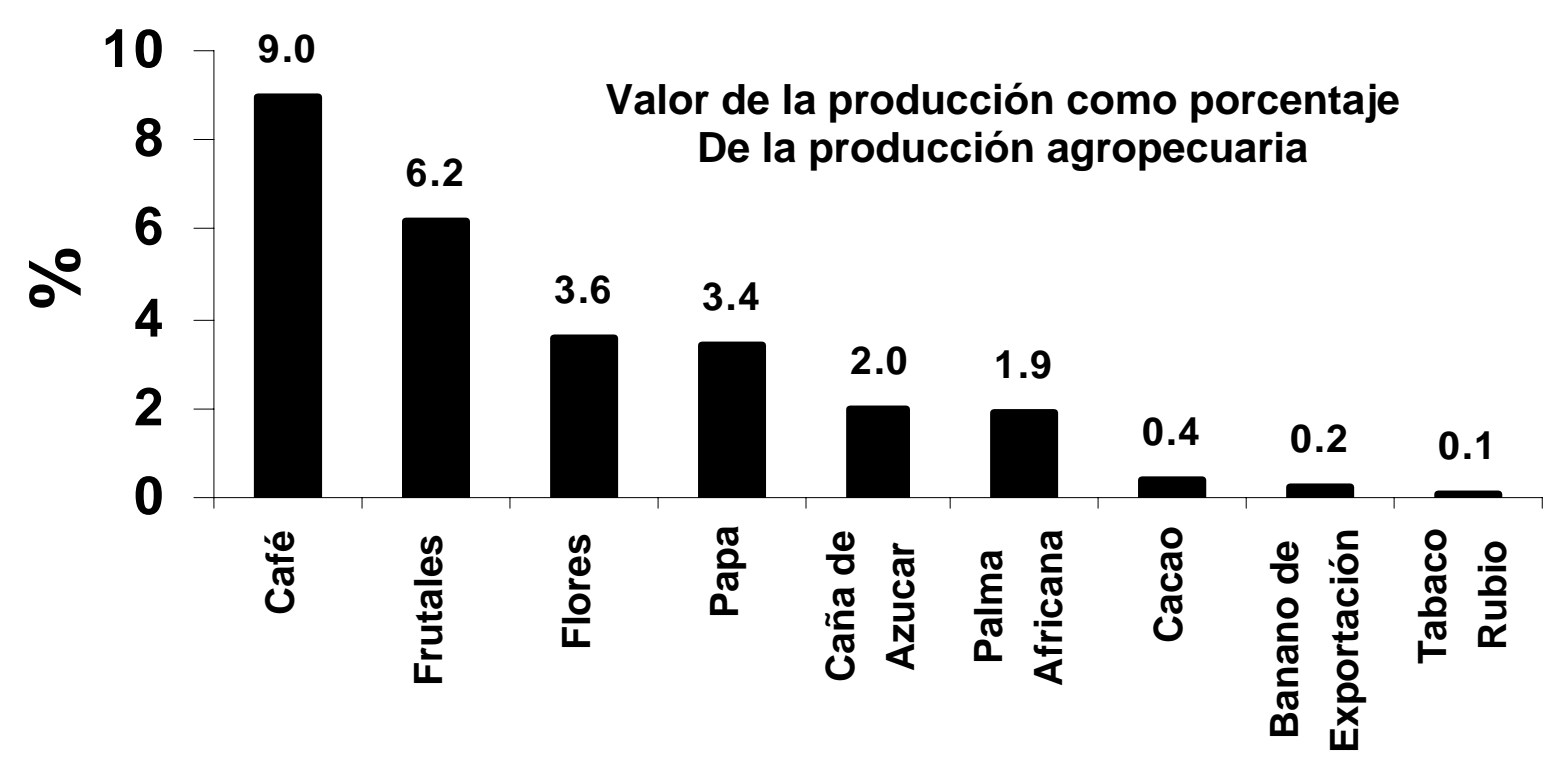

Fuente: Ministerio de Agricultura y Desarrollo Rural, Observatorio Agrocadenas (2001) 
Revista electrónica de difusión científica - Universidad Sergio Arboleda Bogotá - Colombia

http://www.usergioarboleda.edu.co/civilizar Reservados todos los derechos de autor Junio 2005

\subsection{Principales Productos de Exportación}

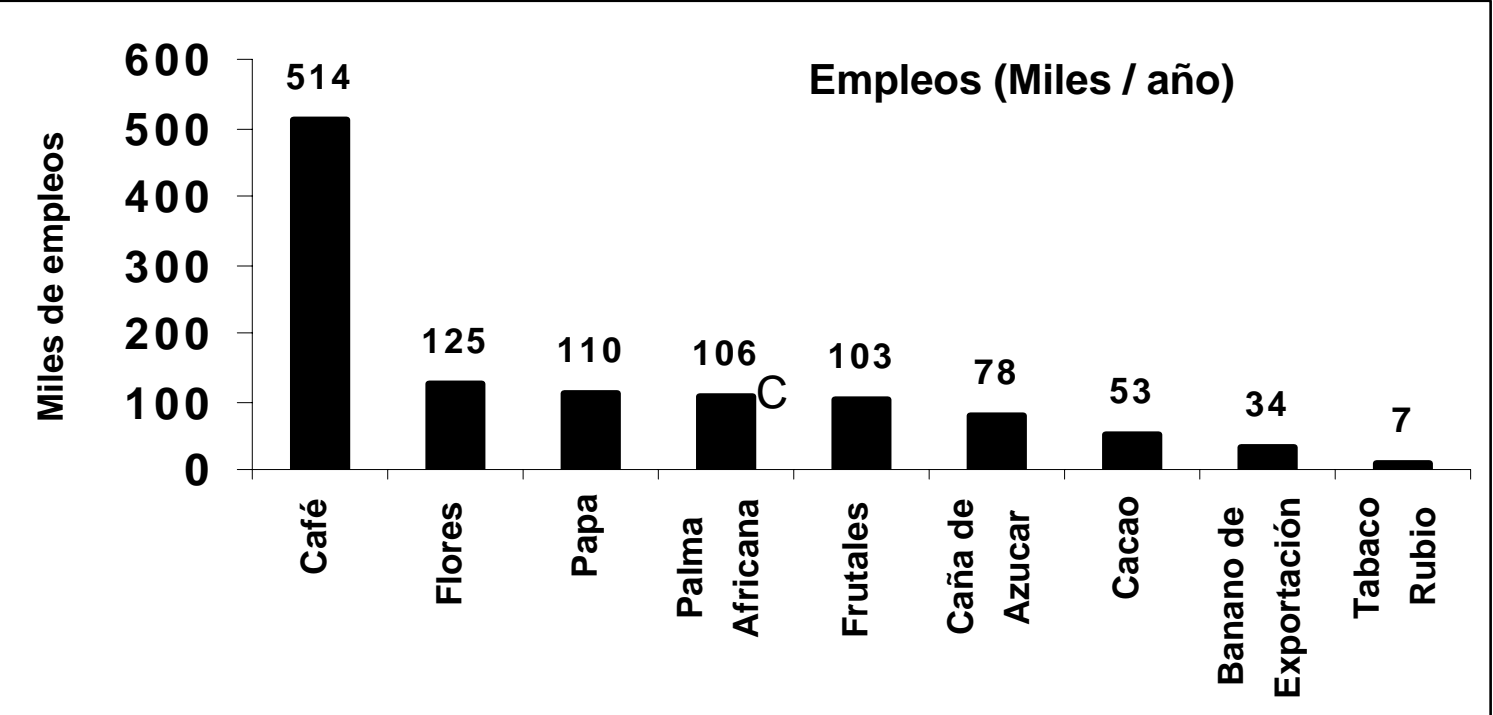

Fuente: Ministerio de Agricultura y Desarrollo Rural, Observatorio Agrocadenas (2001)

\subsection{Principales Productos Importables}

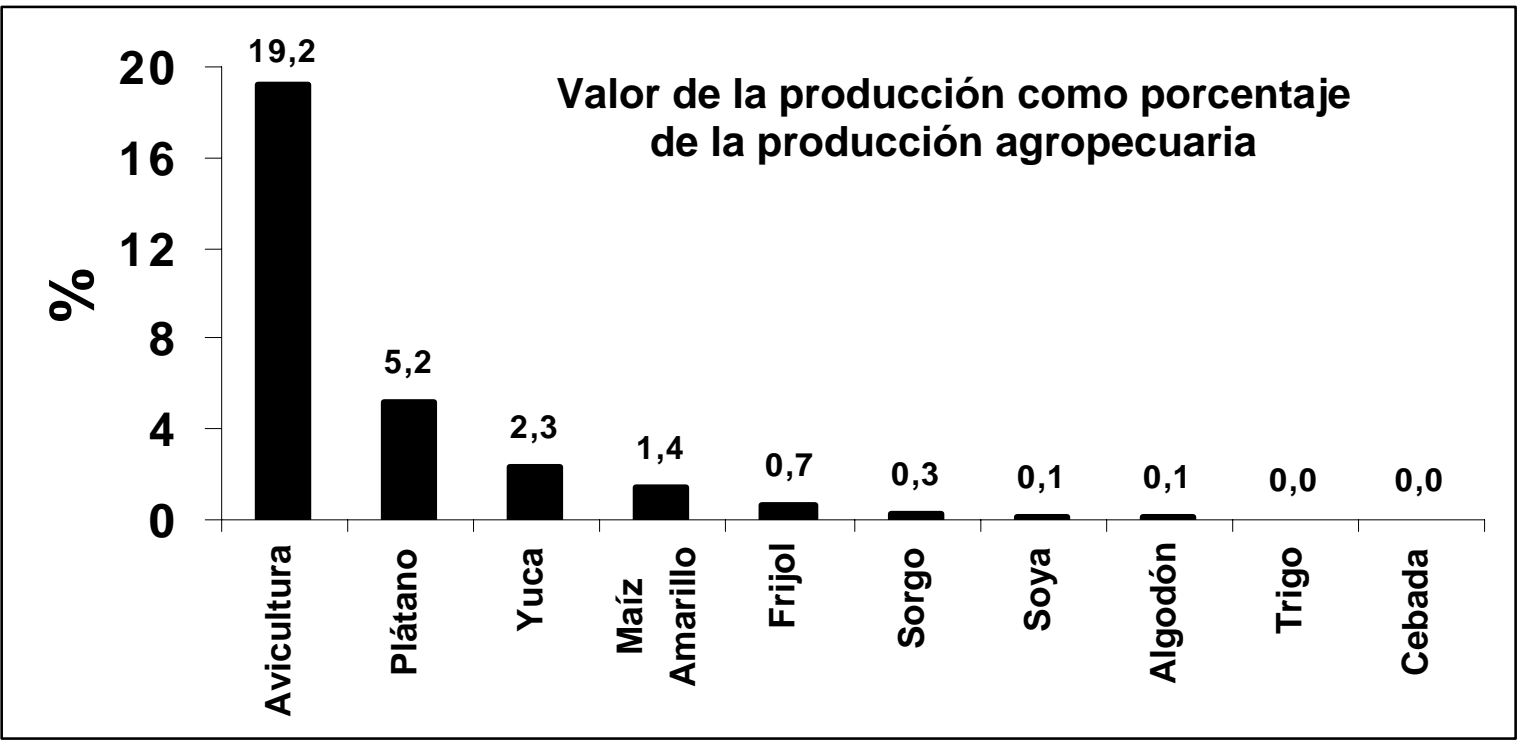

Fuente: Ministerio de Agricultura y Desarrollo Rural, Observatorio Agrocadenas (2001) 


\subsection{Principales productos importables}

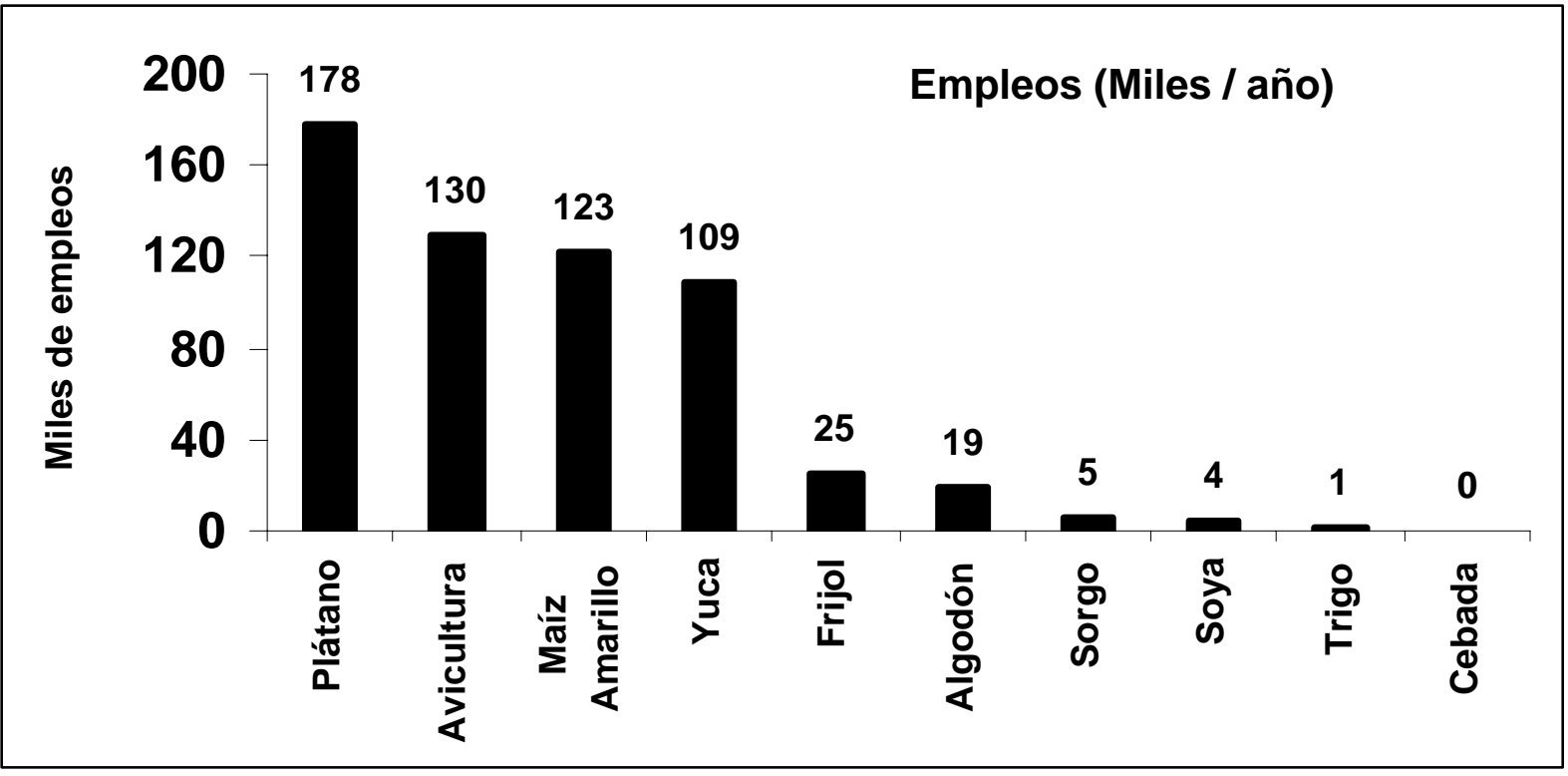

Fuente: Ministerio de Agricultura y Desarrollo Rural, Observatorio Agrocadenas (2001)

\subsection{Productos Importables /Exportables}

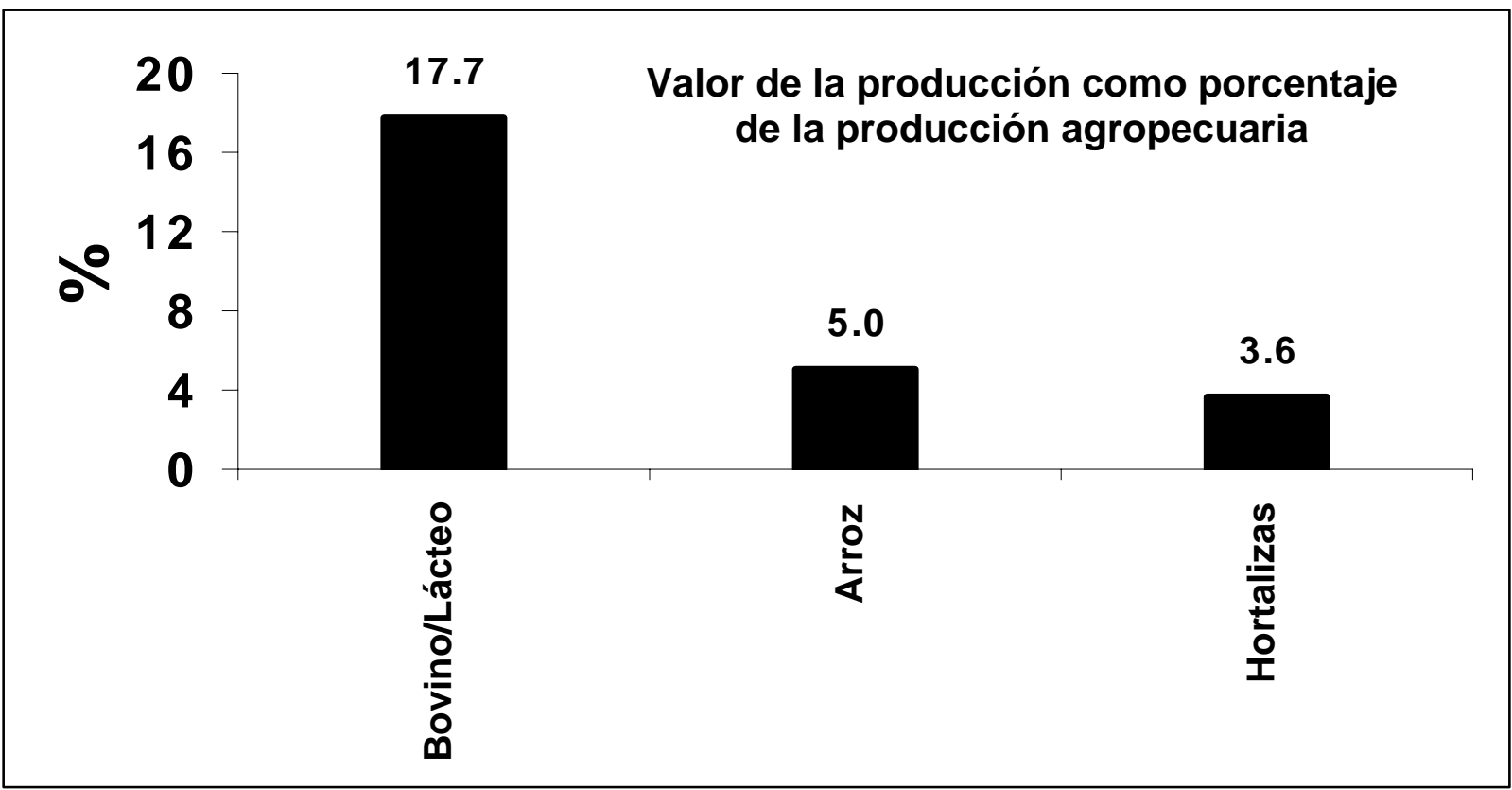

Fuente: Ministerio de Agricultura y Desarrollo Rural, Observatorio Agrocadenas (2001) 


\subsection{Productos Importables/Exportables}

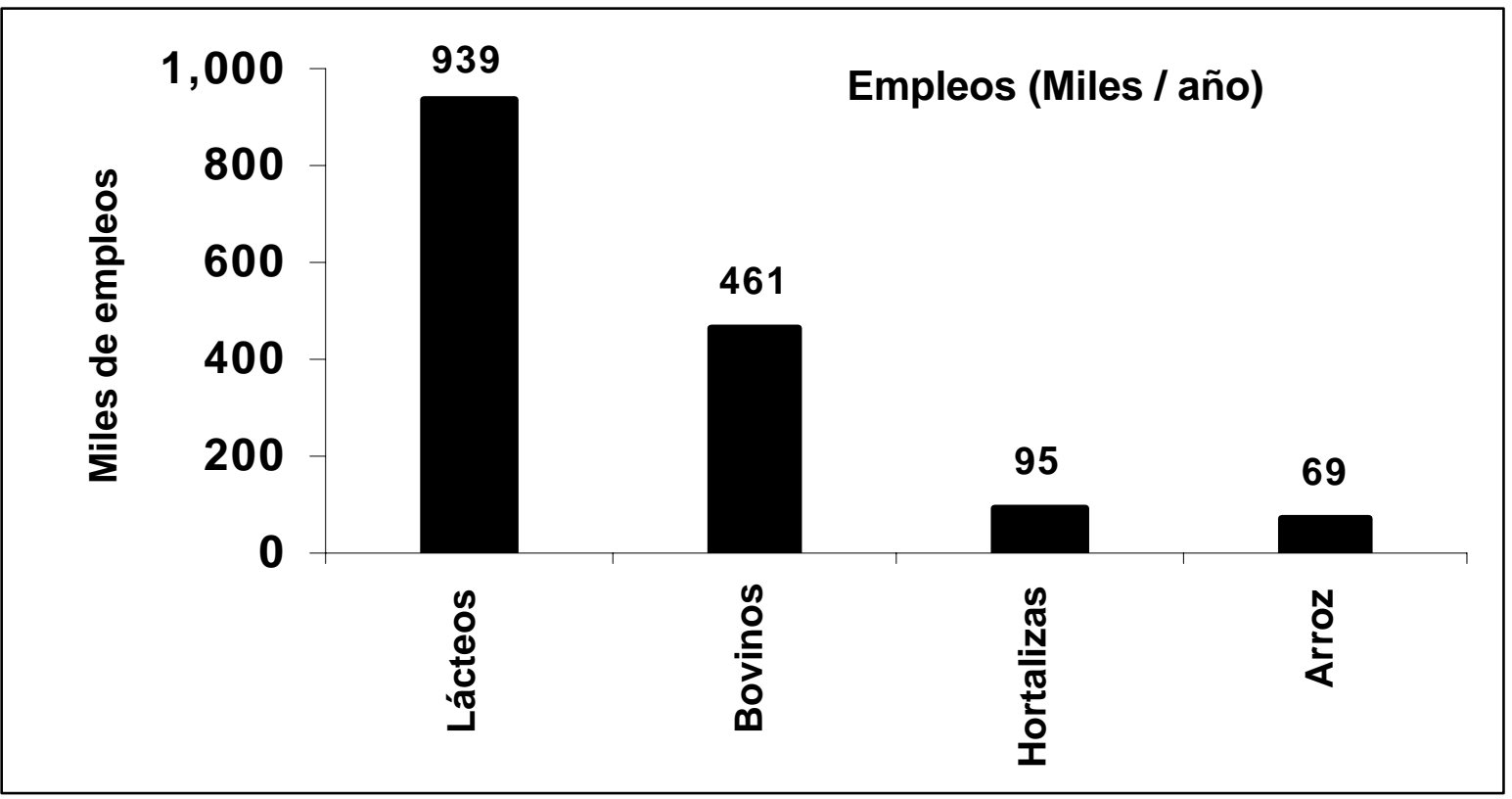

Fuente: Ministerio de Agricultura y Desarrollo Rural, Observatorio Agrocadenas (2001)

Con base en estos antecedentes y considerando que este sector (particularmente el de las frutas y hortalizas) tiene grandes oportunidades en los mercados de los países desarrollados, siempre y cuando se logre "un acceso real" a este mercado, es decir que se superen las trabas y obstáculos que emergen, principalmente, de las medidas sanitarias y fitosanitarias vigentes en los EEUU², se ha venido trabajando este proyecto de investigación con el objetivo general de que, mediante la adecuación de la teoría de la internacionalización a las características del entorno económico colombiano, diseñar y aplicar un modelo o

\footnotetext{
${ }^{2}$ Debe desarrollarse un trabajo investigativo exploratorio sobre el costo de la implementación de las normas vigentes para la importación de productos del agro en los principales países con potencial para nuestras exportaciones.
} 
proceso viable de internacionalización para las micro, pequeñas y medianas empresas del sector agroindustrial del país, ajustado a la economía colombiana.

De acuerdo con la información procesada y ordenada, obtenida de fuentes primarias (cuestionarios, encuestas y entrevistas con empresarios) y de fuentes secundarias (diferentes publicaciones nacionales e internacionales), se han obtenido resultados que, en algunos casos ratifican los presentados en nuestro anterior informe de avance y en otros nuevos que nos están conduciendo al logro de respuestas a nuestras preguntas de investigación, a los objetivos y a las hipótesis planteadas.

Estos nuevos resultados que sustentan el cumplimiento de los objetivos y dan una respuesta a la pregunta del proyecto, comprueban nuestras hipótesis de primer y segundo grado y nos llevan a elaborar las primeras conclusiones, como se verá a continuación:

1. En general, las PyMEs agroindustriales están enfocadas al mercado interno, no cuentan con un plan estratégico definido como "cluster" y su capacidad de marketing se encuentra muy poco desarrollada.

2. No existe en las PyMEs objeto de la investigación una clara vocación exportadora y por ende no existe la capacidad de efectuar un mercadeo estratégico ni existen desarrollos de carácter funcional desde el punto de vista tanto de la gestión internacional como de las prácticas tecnológicas. 
3. Las PyMEs agroindustriales del sector hortofrutícola tienen como producto líder a una gama de bienes involucrados en la definición de productos de conserva y solo las medianas empresas se destacan por adicionar mayor valor agregado y estar más enfocadas al mercado externo.

4. La competitividad de las eventuales exportaciones de productos agroindustriales se ha venido centrando exclusivamente en la reducción de costos laborales y de aranceles y en la favorabilidad de la tasa de cambio y por ello, para no depender de estas variables, cobra importancia la necesidad de avanzar en el desarrollo del proceso de internacionalización, entendiendo como tal el desarrollo de productos de acuerdo con la demanda de determinados nichos del mercado mundial, con valor agregado de conocimiento especializado, vendido a consumidores finales a precios del mercado foráneo de destino.

5. Tal como lo señalaron los resultados mostrados en nuestro informe anterior, los productos orgánicos, también llamados biológicos o ecológicos, obtenidos a través de sistemas de producción sostenible, que no presentan residuos químicos y en su sistema de producción no utilizan fertilizantes, pesticidas ni reguladores de crecimiento, continúa siendo el sector con una oferta mundial de productos orgánicos que no alcanza a satisfacer la demanda creciente en cuanto a variedad y cantidad tanto para consumo fresco como procesado, teniendo el mayor potencial de ventas en los mercados externos aquellos productos con una buena 
relación precio-volumen, tales como las hierbas y plantas aromáticas, medicinales y saborizantes, donde la importante biodiversidad colombiana ofrece muy buenas oportunidades.

6. Para impulsar la competitividad de esos productos es indispensable la implementación de programas orientados a fortalecer y mejorar la calidad del capital humano y a incrementar la productividad laboral.

7. Dada la gran variedad de productos agroindustriales debe hacerse un análisis de referenciación competitiva regional a partir de "clusters" estratégicos, identificando capacidades y vocación exportadora, así como potencialidades y experiencias valiosas en la inserción internacional, si la hubiese.

8. Entre las empresas y productos agroindustriales estudiados existen aquellos que muestran un agotamiento de sus ventajas competitivas derivadas de su localización y presentan un insignificante desarrollo de ventajas competitivas basadas en la diferenciación, además de una clara dificultad en la cooperación interempresarial para lograr la asociatividad, indispensable para la conformación de consorcios exportadores, el modelo de penetración a los mercados externos que más recomendamos. Debe tenerse en cuenta que el agrupamiento permite, además, ventajas comparativas por el acceso a la materia prima (frutas exóticas y verduras) con relativos costos bajos de adquisición.

9. Se encuentra una representación alta del sector empresarial informal, lo que no permite conocer la realidad económica y financiera del sector que, 
por otra parte, muestra mínimos y deficientes conocimientos del mercado nacional e internacional y de sus variables, con políticas comerciales estrechas que le impiden optar por otros clientes o canales de distribución.

10.Al estudiar el Sistema de Indicadores de Competitividad Departamental (SICD), desarrollado por el grupo consultor CID-Universidad Nacional, se encontró que si bien Bogotá se encuentra entre las regiones colombianas de mayor competitividad, Cundinamarca se encuentra entre los departamentos ubicados en la zona media del estudio realizado. No obstante lo anterior Bogotá y Cundinamarca son la ciudad y la región del país que más rápidamente pueden responder al crecimiento de las exportaciones por varios motivos, entre ellos, por tener un mercado interno importante, que permite apalancar un proyecto de exportaciones sobre el propio mercado interno.

11.Al cotejar los productos dinámicos en la demanda mundial de los 16 países con los cuales Colombia tiene un más activo comercio, contra las empresas que ya producen bienes y que han realizado exportaciones desde Bogotá y Cundinamarca, se llegó a una selección de ocho cadenas principales de productos con claras oportunidades de penetración al mercado mundial, entre las cuales se destaca la de alimentos (frutas, hortalizas, aceites y grasas) ${ }^{3}$

\footnotetext{
${ }^{3}$ Plan Estratégico Exportador de Bogotá y Cundinamarca - Cámara de Comercio de Bogotá
} 
12.Dentro de la estrategia para impulsar la exportación de productos para alcanzar el promedio mundial de exportaciones per cápita, se considera indispensable desarrollar o adecuar las condiciones de las PyMEs y del entorno, para potenciar el sector de las hortalizas, frutas, peces, lácteos, cereales, aceites esenciales y flores. ${ }^{4}$ que tienen perspectivas en los mercados mundiales, especialmente al organizarlas para la producción de agricultura orgánica.

13. Bajo los principios de la OMC, la exportación de productos agrícolas está limitada por la necesidad de probar su condición, así como la seguridad de no transportar enfermedades de plantas o animales. Toda nueva exportación de estos productos propuesta desde un país a otro, que nunca haya recibido estos productos, debe ser evaluada con base en un Análisis de Riesgo de Plagas (ARP), para el cual Estados Unidos le ha sugerido a Colombia prepararse para ser capaz de realizar estos estudios y habilitarla para los nuevos productos exportables a ese país.

\section{EL TLC CON LOS EEUU Y LAS MIPYMES AGROINDUSTRIALES}

El actual Plan Nacional de Desarrollo "Hacia un Estado Comunitario" establece dentro de sus estrategias para lograr el crecimiento económico, la búsqueda de acceso permanente a los mercados internacionales mediante la suscripción de acuerdos de libre comercio. En desarrollo de lo anterior, el Gobierno Nacional suscribió un acuerdo comercial con México y Venezuela (Grupo de los Tres) y uno con el Mercado Común del Sur (MERCOSUR) y viene

\footnotetext{
${ }^{4}$ Ibidem
} 
adelantando negociaciones para la firma de un acuerdo de libre comercio con los Estados Unidos.

Teniendo en cuenta lo anterior y especialmente, las preocupaciones de los analistas del TLC con Estados Unidos sobre el futuro del sector agropecuario y del sector de las MiPYMEs, creemos que ellas podrían ser despejadas, al considerar que las pequeñas y medianas empresas agroindustriales (particularmente el de las hortalizas y frutas exóticas) tienen grandes oportunidades en los mercados de los países desarrollados, particularmente el de los Estados Unidos, sí nos unimos todos en el objetivo general de que, mediante la adecuación de la teoría de la internacionalización a las características del entorno económico colombiano, se desarrolle un proceso viable de internacionalización de esas empresas para convertirlas en el motor de desarrollo de nuestra economía.

Esta internacionalización del sector agroindustrial que proponemos y no obstante las distorsiones que este sector presenta en el mercado mundial, que desvirtúan la economía de libre mercado, consideramos puede ser alcanzada dadas las claras ventajas comparativas que ofrece el país como son: riqueza y diversidad de sus recursos naturales, estratégica situación geográfica con cosechas todo el año, relativo mínimo tiempo de transporte a mercados internacionales estacionales, colonias latinas (38 millones de personas en Estados Unidos con muy buen poder de compra), que añoran los productos tropicales y 
ahora, la liberación del comercio que puede obtenerse al negociarse bien el TLC con Estados Unidos.

Sí las MiPyMEs colombianas iniciaran un desarrollo parecido a sus homólogas de otros países (Taiwan, Italia, Corea, entre otros), grande sería su aporte a la balanza de pagos (en peligro de ser deficitaria por el aumento de las importaciones y la disminución de las exportaciones petroleras), para lo cual es necesario poner en marcha, gobierno, academia y empresarios, un sostenido proceso de internacionalización, entendido éste como el proceso de desarrollar productos de acuerdo con la demanda de determinados nichos del mercado mundial, con valor agregado de conocimiento especializado, vendido a precios del mercado foráneo de destino y estableciendo marcas propias, para llegar con los numerosos productos colombianos que ofrecen claras ventajas competitivas a los mercados mundiales, aprovechando así las oportunidades competitivas, las opciones y ventajas tecnológicas y los incentivos gubernamentales. Todos deberíamos tener en cuenta que la estrategia internacional de la empresa debe ser, cada vez más, un aspecto esencial de la estrategia global de la misma.

Para ello, el país debe superar los serios obstáculos que hoy afronta el sector como es la falta de financiación adecuada y oportuna, la carencia de capacitación y formación en gestión gerencial internacional (muy pocas mipymes saben que es el G3, el Convenio CAN-MERCOSUR y el TLC en negociación), tienen un limitado acceso a tecnologías especialmente en las referentes al 
Revista electrónica de difusión científica - Universidad Sergio Arboleda Bogotá - Colombia

http://www.usergioarboleda.edu.co/civilizar Reservados todos los derechos de autor Junio 2005

comercio exterior y existen las barreras burocráticas, todos los cuales dificultan el desarrollo de sus empresas y en muchos casos las han llevado a su fracaso.

\section{RESULTADOS Y RECOMENDACIONES ${ }^{5}$}

A esta altura del desarrollo de la investigación y de acuerdo a la información procesada, obtenida de fuentes primarias y secundarias, en la investigación adelantada sobre el tema por el Grupo de Investigación y Desarrollo de MiPyMEs de la Universidad Sergio Arboleda, creemos posible presentar ya algunos resultados que nos permiten hacer diversas recomendaciones para desarrollar varias estrategias a ser incluidas en el modelo de internacionalización de las PyMEs agroindustriales colombianas que nos hemos propuesto, entre las cuales destacamos los mecanismos a ser utilizados en el proceso de internacionalización de las PyMEs agroindustriales que explicamos más adelante.

\section{DESARROLLO DE FRANQUICIAS EN EL EXTERIOR}

Dado el crecimiento que ha tenido la modalidad comercial de las franquicias en todo el mundo y especialmente en los Estados Unidos, este es un campo que debería investigarse profundamente y como tal se ha venido haciendo ${ }^{6}$, como un medio óptimo de llegar a tener marcas propias y la venta directa al consumidor final de los productos agroindustriales colombianos en ese mercado.

\footnotetext{
${ }^{5}$ En la actualidad se adelanta un trabajo de campo-mediante encuestas- a un grupo de PyMEs seleccionadas de la base de datos de la Cámara de Comercio de Bogotá que servirá para actualizar y validar la información obtenida en las encuestas anteriores.

${ }^{6}$ Un trabajo investigativo completo sobre este mecanismo -complementario de esta investigaciónse ha venido adelantando dentro de la línea de investigación de la problemática de las PyMEs
} 
Este modelo de expansión, una vez definido su concepto de negocio y comprobado su éxito empresarial, puede ser llevado al exterior por empresarios pequeños y medianos del sector agroindustrial, considerando que éste puede ser eficaz no solo en Colombia sino en el exterior y en particular en los Estados Unidos, para lo cual deben prepararse y estructurar su concepto de negocio adecuadamente.

La internacionalización de las pequeñas y medianas empresas agroindustriales colombianas podría alcanzarse a través de la utilización del sistema de franquicias, en el cual la colonia colombiana y latina en general sería la población mejor opcionada para ser franquiciada, como paso inicial del posicionamiento de los productos agroindustriales colombianos, aprovechando ese nicho del "mercado de la nostalgia" y cuya capacidad de ahorro, demostrada a través de las remesas anuales por valor superior a los US\$3.000 millones, podría ser la base para establecer las cadenas de productos nacionales.

Por lo tanto, no es solo mediante la exportación de sus productos agroindustriales como puede el sector internacionalizarse. La franquicia es una alternativa para las empresas de este sector para acceder a los consumidores de Estados Unidos, como ya lo han hecho algunas empresas colombianas que han logrado internacionalizarse a través de franquicias, reconociendo que el camino no es fácil dado lo estricto de la legislación estadounidense con respecto a la apertura 
de negocios de comida y adicionalmente, estas dificultades inherentes a los negocios de franquicias para alimentos se multiplican cuando se otorgan a empresas extranjeras.

Esto no debe desanimar a los empresarios colombianos del sector agroindustrial interesados en expandir sus negocios al mercado de Estados Unidos en el marco del TLC, ya que los beneficios que pueden alcanzar los que se decidan por esta estrategia comercial son muy grandes para ellos y para la economía colombiana en general.

Por lo tanto, el Tratado de Libre Comercio con Estados Unidos deben mirarlo como un gran reto por parte de las PyMEs agroindustriales colombianas que se propongan ingresar con sus productos a ese mercado a través del sistema de franquicias y aprovechar así las inmensas oportunidades para llegar a un mercado con un potencial inicial de 38 millones de hispanoamericanos, olvidando el paradigma de que solo las grandes empresas pueden ser franquiciadoras.

\section{INVERSIÓN EXTRANJERA DIRECTA}

Las PyMEs agroindustriales colombianas, deben evaluar la firma del tratado de libre comercio con los Estados Unidos como la gran oportunidad de desarrollo y mejoramiento tecnológico, especialmente si tenemos en cuenta que éste les ofrece la oportunidad de conseguir recursos de capital privado para financiar su crecimiento a largo plazo, tanto proveniente de ese país cómo de otros países 
interesados en penetrar al mercado más grande del mundo, con todas las ventajas que la inversión extranjera directa significa.

La oportunidad la vemos mucho mejor si estudiamos los aranceles (17\% en promedio) que pagan las importaciones de terceros países frente a la producción colombiana que ingresa al mercado americano sin arancel, convirtiéndose por este solo factor en un muy importante proveedor potencial, más aún cuando hay muchas empresas estadounidenses que no van a poder subsistir por mucho tiempo más y tendrán que moverse para competir en un mercado global, pudiendo en lugar de cerrar sus puertas, trasladarse a Colombia en un "joint venture" con alguna pyme colombiana. Y lo mismo podría resultar para cualquier empresa domiciliada en un país que no tuviera suscrito un TLC con los Estados Unidos., por ejemplo, las empresas chinas, indias, coreanas, etc.. grandes exportadoras de productos agroindustriales a los EEUU y quisieran continuar participando de ese gran mercado, el más grande del mundo.

Para lograr consolidar estas favorables coyunturas, al tiempo que sería indispensable que Colombia desarrolle rápidamente una agresiva estrategia que impulse y facilite el desarrollo y consolidación de iniciativas de inversión extranjera en el país, para que el mundo considere a Colombia como un excelente lugar para localizar producciones y componentes destinados a los países desarrollados, que genere en nuestro pequeño y mediano empresario una cultura que lo lleve a considerar seriamente a la inversión extranjera como opción de desarrollo para su 
empresa, por cuanto debe reconocerse que es un número mínimo los empresarios de este sector que la han considerado como vehículo de crecimiento y desarrollo.

En esta forma, el TLC podría ser la plataforma de internacionalización de nuestras pequeñas y medianas empresas, aprovechando estas oportunidades y otras, para la ubicación en Colombia, de muchas empresas que, de acuerdo a una encuesta global realizada por Naciones Unidas en diversos países entre expertos en este tipo de decisiones, la reubicación de actividades productivas está incluida en los planes de localización de los próximos tres años por parte de muchas organizaciones, con lo que se producirá un auge de inversión extranjera directa en el mundo, de la cual, dada la especial circunstancia colombiana, podría ser nuestras pymes agroindustriales las grandes beneficiadas.

Y nuestra mayor ventaja, es el tamaño de nuestro mercado doméstico que, con 44.6 millones de habitantes, es superior al de todas las repúblicas centroamericanas juntas y es mayor a Perú y Ecuador juntos. Esto es muy importante para el inversionista extranjero en la medida que puede implementar sus planes de negocios contemplando tanto el mercado externo como el interno.

Por eso, nuestra nación que ha visto disminuir sus inversiones en gestión empresarial y en las nuevas tecnologías, de no verlas aumentadas sustancialmente mediante la inversión extranjera directa, está condenada a 
mostrar desventajas competitivas que serán las ventajas de sus contrapartes en el comercio internacional.

\section{ASOCIATIVIDAD EMPRESARIAL}

La necesidad de unir esfuerzos para enfrentar competitivamente los retos del actual mundo de los negocios, obliga a promover el tema de la asociatividad, entendida como el mecanismo de cooperación integral entre las PyMEs agroindustriales, alrededor de objetivos, propósitos y metas comunes, en donde cada empresa participante, manteniendo su independencia jurídica y autonomía gerencial, decide voluntariamente participar en un esfuerzo conjunto con los otros participantes para la búsqueda de ese objetivo común.

Dado que la inserción en el mercado internacional no es una tarea fácil ni se encuentra al alcance de cualquier empresa, por grande que ella sea, especialmente si se trata de una PyME, ya que ello le exigirá no solo el cambio de una cultura "mediterránea" sino la implementación de algún tipo de modernización o adaptación en lo que hace relación tanto a sus estrategias de marketing y venta como a todas las demás actividades de su cadena de valor. Y ello no es fácil superar los obstáculos que esta reingeniería significa- si lo pretende hacer individualmente, dado el volumen de recursos financieros, humanos y técnicos que, en la mayoría de los casos se encuentran fuera del alcance del sector empresarial de la PyME colombiana. 
Revista electrónica de difusión científica - Universidad Sergio Arboleda Bogotá - Colombia

http://www.usergioarboleda.edu.co/civilizar Reservados todos los derechos de autor Junio 2005

En relación con todo lo anterior, la experiencia internacional de las décadas pasadas muestra con claridad que, en relación con varios de los problemas señalados, la cooperación y articulación de esfuerzos entre empresas contribuye eficazmente a resolver o suavizar tales restricciones. En función de ello, consideramos que un trabajo investigativo ${ }^{7}$ sobre como apoyar e incentivar entre las pequeñas y medianas empresas- el desarrollo de la ASOCIATIVIDAD puede traducirse en la mejora del comportamiento de las PyMEs agroindustriales en el mercado interno (medidas pro competitivas) como en la forma de alcanzar mejores condiciones para uiniciar su proceso de internacionalización.

Para ello, es necesario desarrollar un programa dirigido a aumentar su capacidad competitiva, facilitando y fortaleciendo la formación de operaciones cooperativas entre empresas vinculadas y participando en otras áreas del desarrollo económico, así como a facilitar relaciones de confianza más sólidas entre las empresas participantes.

\section{ESTRATEGIA DE E-COMMERCE MEDIANTE B2C}

El valor de las exportaciones que ha venido haciendo el sector no tiene mayor significado en el total de las exportaciones colombianas y mucho menos si se consideran las oportunidades que ofrece el mercado mundial, debido

\footnotetext{
${ }^{7}$ El autor participa en el trabajo de grado sobre la Asociatividad Empresarial, para optar al título del Master Executive en Administración de Empresas y Liderazgo, de la Escuela de Negocios de la Universidad San Pablo-CEU
} 


\section{GIVILIZAR}

Revista electrónica de difusión científica - Universidad Sergio Arboleda Bogotá - Colombia

http://www.usergioarboleda.edu.co/civilizar Reservados todos los derechos de autor Junio 2005

especialmente a que los productos de las PyMEs del sector no llegan al consumidor final al estar exportando a precios colombianos y no del mercado de destino a través de intermediarios que se quedan con el $80 \%$ del precio final.

La creación de una tienda en línea que promocione y venda productos agroindustriales colombianos, principalmente a los latinos residentes en Estados Unidos (37 millones con buen poder de compra) es una excelente estrategia, para lo cual es necesario converger dos universos muy dispares: por un lado, está el mundo del Internet, la alta tecnología y el B2C y, por otro, el de la cultura y de sus productos tradicionales.

\section{CONCLUSIÓN}

Creemos que la implementación de estas estrategias o mecanismos que hemos propuesto, junto con otras que hemos venido estudiando para superar debilidades del sector, tales como la falta de financiación adecuada y oportuna, la carencia de capacitación y formación en gestión internacional y su limitado acceso a las tecnologías de la información y comunicaciones, puede contribuir positivamente a desarrollar internacionalmente un sector que ofrece múltiples posibilidades no solo de generación de divisas sino de creación de nuevas fuentes de trabajo y de impulso al desarrollo social del país. 